\title{
NHÂN TỐ ẢNH HƯỞNG ĐẾN SAI SÓT TRÊN BÁO CÁO TÀI CHÍNH CỦA CÁC DOANH NGHIỆP NHỎ VÀ VÙ̀A
}

\author{
ĐOÀN THỊ THÙY ANH, HỒ THỊ MỸ GIANG, NGUYẼ̃N THI YẾN NGUYÊN, NGUYẼ̃N THI \\ PHƯƠNG THẢO, LÊ THI NGỌC TUYỀN \\ Khoa Kế toán kiểm toán, Truờng Đại học Công nghiệp thành phố Hồ Chi Minh \\ doanthithuyanh@iuh.edu.vn
}

Tóm tắt. Hiện nay có nhiều nghiên cứu về nâng cao chất lượng thông tin trên báo cáo tài chính tại các doanh nghiệp niêm yết trên thị trường chứng khoán nhưng vấn đề này lại ít được quan tâm tại các doanh nghiệp nhỏ và vừa. Nghiên cứu sử dụng phương pháp nghiên cứu hỗn hợp bao gồm phương pháp định tính (phỏng vấn chuyên gia) và phương pháp định lượng như phân tích nhân tố khám phá EFA, phân tích hồi quy để xác định và đo lường các nhân tô ảnh hưởng đến sai sót trên $\mathrm{BCTC}$. Nghiên cứu tiến hành khảo sát người hành nghề kế toán tại các doanh nghiệp và các chuyên gia trong lĩnh vực kế toán với số mẫu hợp lệ là 150 mẫu. Kết quả cho thấy hệ thống kiểm soát nội bộ, năng lực nhà lãnh đạo, môi trường pháp lý, kế hoạch đào tạo và bồi dưỡng, năng lực kế toán viên và hệ thống thông tin kế toán tại doanh nghiệp là các yếu tố tác động đến việc sai sót trong kế toán. Từ kết quả của nghiên cứu này, một số ý kiến được đề xuất nhằm hạn chế các sai sót và nâng cao chất lượng thông tin hữu ích cho các doanh nghiệp nhỏ và vừa tại Việt Nam.

Từ khóa. Sai sót báo cáo tài chính, doanh nghiệp vừa và nhỏ, chất lượng báo cáo tài chính.

\section{FACTORS AFFECTING THE FINANCIAL STATEMENT ERRORS OF SMALL AND MEDIUM ENTERPRISES (SMES)}

\begin{abstract}
Currently, there are many studies on improving the quality of information on financial statements in companies listed on the stock market, but this issue is of little concern in small and medium enterprises. To identify the impact factors and measure their impact the financial statement errors SMEs, The author uses the mixed methods herein: qualitative research are used by semi - structured in depth interview and quantitative research method combined with analysis tools EFA (Exploratory Factor Analysis), linear regression analysis in order to process data from qualitative research results. The study surveyed accounting practitioners in enterprises and experts in the accounting field with a valid sample number of 150 samples. The results show that internal control system, leadership capacity, legal environment, training and retraining plan, accountant capacity, and accounting information system in enterprises are all factors that contribute to the impact on errors in accounting. From the results of this study, several suggestions are proposed to limit errors and improve the quality of useful information for SMEs in Vietnam.
\end{abstract}

Keywords. Errors in financial statements, small and medium enterprises, quality of financial statements.

\section{GIỚI THIẸU}

Thông tin trên báo cáo tài chính $(\mathrm{BCTC})$ là một trong những thông tin quan trọng giúp cho người sử dụng ra các quyết định kinh tế - tài chính. BCTC tại các doanh nghiệp theo quy định của pháp luật bắt buộc phải kiểm toán trước khi nộp sẽ tin cậy hơn đối với các doanh nghiệp chưa được kiểm toán. Tuy nhiên, tại doanh nghiệp siêu nhỏ, nhỏ và vừa theo quy định không bắt buộc phải kiểm toán thì quá trình lập và trình bày $\mathrm{BCTC}$ tại các doanh nghiệp này còn tồn tại nhiều sai sót chưa được phát hiện dẫn đến làm giảm chất lượng thông tin trên báo cáo tài chính. Điều này ảnh hưởng trực tiếp đến việc cung cấp thông tin hữu ích cho nhà quản lý doanh nghiệp, chủ nợ, cơ quan nhà nước trong việc đưa ra các chính sách pháp luật. Hiện nay tính trên quy mô doanh nghiệp cả nước, tỷ lệ doanh nghiệp quy mô siêu nhỏ và nhỏ chiếm tỷ lệ cao nhất, khoảng $93,7 \%$, doanh nghiệp quy mô vừa chiếm $3,5 \%$ và doanh nghiệp quy mô lớn chiếm $2,8 \%$ (Bộ kế hoạch và Đầu tư (2020)). Qua số liệu thống kê cho thấy rằng, các doanh nghiệp hoạt động tại Việt Nam chủ yếu có 
quy mô siêu nhỏ, nhỏ và vừa. Các nghiên cứu về sai sót thông tin trên $\mathrm{BCTC}$ có các nghiên cứu của một số tác giả như Nguyễn Công Phương và cộng sự (2018), Phạm Lê Ngọc Tuyết (2020). Các nghiên cứu này dựa vào cách tiếp cận mô tả, so sánh các thông tin công bố trước và sau kiểm toán để thực hiện giải thích hiện tượng sai sót. Do đó chưa tìm thấy một nghiên cứu nào về sai sót tại các doanh nghiệp nhỏ và vừa tại Việt Nam. Bài nghiên cứu hướng tới việc tìm hiểu các nguyên nhân tác động tới sai sót trên báo cáo tài chính trong quá trình thực hiện công việc kế toán. Nghiên cứu này sẽ giúp doanh nghiệp có định hướng trong quá trình hoàn thiện công tác kế toán góp phần nâng cao chất lượng BCTC.

\section{CƠ SỞ LÝ THUYẾT}

\subsection{Tổng quan về sai sót.}

Chuẩn mực kiểm toán Việt Nam số 200 "Mục tiêu tổng thể của kiểm toán viên và doanh nghiệp kiểm toán khi thực hiện kiểm toán" định nghĩa sai sót "là sự khác biệt giữa giá trị, cách phân loại trình bày hoặc thuyết minh của một khoản mục trên $\mathrm{BCTC}$ so với khuôn khổ về lập và trình bày $\mathrm{BCTC}$ được áp dụng. Sai sót có thể phát sinh do nhầm lẫn hoặc gian lận". Cũng theo chuẩn mực Kiểm toán Việt nam số 240 thì "Gian lận là hành vi cố ý do một hay nhiều người trong ban quản trị, ban giám đốc, các nhân viên hoặc bên thứ ba thực hiện bằng các hành vi gian dối để thu lợi bất chính hoặc bất hợp pháp." Như vậy, sai sót có thể là những hành vi do không cố ý vì nhầm lẫn hoặc do những hành vi cố ý để thu lợi bất chính về cho bản thân hoặc tổ chức.

Trong chuẩn mực kế toán Việt Nam số 29 về "Thay đổi các chính sách kế toán, ước tính kế toán và các sai sót", khái niệm sai sót được hiểu là "Sai sót có thể phát sinh từ việc ghi nhận, xác định giá trị, trình bày và thuyết minh các khoản mục trên $\mathrm{BCTC}$. $\mathrm{BCTC}$ được coi là không phù hợp với chuẩn mực kế toán và chế độ kế toán nếu chúng có các sai sót trọng yếu hoặc các sai sót không trọng yếu nhưng cố ý trình bày tình hình tài chính, kết quả hoạt động kinh doanh hay các luồng tiền theo một hướng khác". Ngoài ra, đoạn 4 chuẩn mực chỉ ra rằng: "Các sai sót bao gồm sai sót do tính toán, áp dụng sai các chính sách kế toán, bỏ quên, hiểu và diễn giải sai các sự việc và gian lận".

Có thể thấy, trong chuẩn mực kế toán hay chuẩn mực kiểm toán thì sai sót cũng được hiểu là những hành vi cố ý vi phạm hay không cố ý gây thiệt hại cho người sử dụng BCTC nếu đó là sai sót trọng yếu.

Đối với các sai sót xảy ra trong quá trình lập và trình bày báo cáo tài chính, thường xảy ra sai sót như:

Bảng 1: Bảng tổng hợp các sai sót thường gặp trên BCTC

\begin{tabular}{|c|c|c|}
\hline STT & Nội dung & Sai sót \\
\hline 1 & $\begin{array}{l}\text { Chính sách kế } \\
\text { toán, ước tính } \\
\text { kế toán }\end{array}$ & $\begin{array}{l}\text { Lựa chọn phương pháp hạch toán và xác định giá trị hàng tồn kho chưa phù hợp với } \\
\text { đặc điềm của hàng tồn kho. } \\
\text { Xác định kỳ kế toán chưa phù hợp với chu kỳ kinh doanh của doanh } \\
\text { nghiệp. } \\
\text { Xác đị̂n phương pháp khấu hao tài sản cố định chưa phù hợp với đặc điểm của tài } \\
\text { sản cồnh. } \\
\text { Xác định thời gian khấu hao chưa phù hợp với lợi ích kinh tế mà tài sản mang lại. }\end{array}$ \\
\hline 2 & $\begin{array}{l}\text { Các sai sót } \\
\text { trong kỳ }\end{array}$ & $\begin{array}{l}\text { Chứng từ lập, luân chuyển, lưu trữ chưa đúng quy định. } \\
\text { Bỏ sót nghiệp vụ kinh tế phát sinh trong quá trình ghi sổ. } \\
\text { Các giao dịch và sự kiện được ghi nhận sai tài khoản. } \\
\text { Ghi sai số tiền từ chứng từ lên sổ sách kế toán. } \\
\text { Tính giá trị tài sản chưa đúng theo quy định trong chế độ và chuẩn mực. } \\
\text { Ghi nhận tài sản chưa phù hợp. } \\
\text { Doanh thu, chi phí ghi nhận chưa đúng kỳ phát sinh.... }\end{array}$ \\
\hline 3 & $\begin{array}{l}\text { Các sai sót xảy } \\
\text { ra vào cuối kỳ }\end{array}$ & $\begin{array}{l}\text { Không thực hiện kiểm kê, đối chiếu, kiểm tra dẫn đến việc số liệu trên sổ sách không } \\
\text { đúng với thực tể. } \\
\text { Tài sản, nợ phải trả, vốn chủ sở hữu được đánh giá chưa phù hợp khi lập BCTC. }\end{array}$ \\
\hline 4 & $\begin{array}{l}\text { Trình bày và } \\
\text { thuyết minh }\end{array}$ & $\begin{array}{l}\text { Phân loại chưa chính xác tài sản, nợ phải trả ngắn hạn, dài hạn. } \\
\text { Trình bày sai khoản mục. }\end{array}$ \\
\hline
\end{tabular}




\begin{tabular}{|l|l|l|}
\hline & $\begin{array}{l}\text { Các thông tin tài chính chưa được trình bày, diễn giải, thuyết minh hợp lý, dễ hiểu, rõ } \\
\text { ràng. } \\
\text { Trình bày thiếu các chính sách kế toán mà doanh nghiệp áp dụng. }\end{array}$ \\
\hline
\end{tabular}

(Nguồn: Tác giả tư tổng hợp)

Như vậy, để đảm bảo thông tin trên $\mathrm{BCTC}$ được trình bày một cách trung thực, hợp lý thì kế toán cần phải đảm bảo không phát sinh các sai sót từ quá trình lựa chọn và áp dụng chính sách kế toán tại doanh nghiệp, tuân thủ các quy định trong chuẩn mực, chế độ kế toán và các quy định có liên quan hiện hành. Chính vì thế, việc xác định các yếu tố nào tác động làm nguyên nhân dẫn đến sai sót trên $\mathrm{BCTC}$ là vấn đề quan trọng để từ đó doanh nghiệp và cơ quan nhà nước có các giải pháp ngăn ngừa, giảm thiểu các sai sót có thể xảy ra.

\subsection{Các lý thuyết vận dụng vào nghiên cứu}

\subsubsection{Lý thuyết kế toán chuẩn tắc}

Khái niệm "Lý thuyết kế toán chuẩn tắc" được mượn từ khái niệm "Lý thuyết kinh tế học chuẩn tắc" của Friedman (1953). Trong đó lý thuyết kế toán chuẩn tắc nhằm đưa ra các quy định, thủ tục kế toán cụ thể và nội dung trên báo cáo tài chính được cho là phù hợp (Watts \& Zimmerman (1986). Theo tác giả Phan Lê Thành Long (2010) đã khẳng định nội dung cơ bản của lý thuyết kế toán chuẩn tắc diễn giải các quy định của khung nguyên tắc kế toán và các chuẩn mực kế toán.

Lý thuyết này vận dụng trong các nghiên cứu Littleton (1977), Chambers (1966) đề cập về vấn đề ghi nhận và đo lường trong kế toán. Mattessich (1995) dựa trên lý thuyết này để nhấn mạnh vai trò của các quy định trong việc thực hành kế toán.

Ứng dụng nội dung lý thuyết vào đề tài nghiên cứu: Trong kế toán, lý thuyết kế toán chuẩn tắc quy định các thủ tục kế toán yêu cầu người làm kế toán thực hiện như thế nào mà không dựa trên những quan sát thực tế. Do đó, lý thuyết chuẩn tắc trả lời câu hỏi "Người lập Báo cáo tài chính phải làm gì?" mà không lý giải được "Tại sao họ làm như vậy?" hay "Trong thực tế kế toán làm như thế nào?". Có thể thấy rằng, việc xem xét các quy định kế toán được áp dụng thực tế có phù hợp và đạt hiệu quả kinh tế không để đưa ra các điều chỉnh cần thiết là một điều tất yếu và quan trọng ngay từ bây giờ mà kế toán viên phải thực hiện. Như vậy, nghiên cứu đã vận dụng lý thuyết chuẩn tắc vào việc xác định yếu tố môi trường pháp lý có ảnh hưởng đển sai sót trên BCTC.

2.2.2 Lý thuyết thể ché

Trong nghiên cứu của Châu Quốc An (2017) có đề cập lý thuyết thể chế theo định nghĩa của Thorstein Veblen như sau: "Thể chế là tính quy chuẩn của hành vi hoặc các quy tắc xác định hành vi trong những tình huống cụ thể các thành viên của một nhóm xã hội chấp nhận về cơ bản, và sự tuân thủ các quy tắc đó là do bản thân tự kiểm soát hoặc do quyền lực bên ngoài khống chế”. Châu Quốc An (2017) cho rằng thể chế là những quy tắc, quy định do Nhà nước ban hành, và là một yếu tố rất quan trọng trong quá trình phát triển cho nền kinh tế của Việt Nam. Lý thuyết thể chế này được sử dụng trong các nghiên cứu của Amenta và cộng sự (2010) nghiên cứu chính sách công, Biggart và cộng sự (1987) trong việc giải thích quyền của lãnh đạo với các nguyên tắc và chuẩn mực hợp pháp của cấu trúc xã hội.

Vận dụng lý thuyết thể chế vào kế toán, cho thấy sự liên quan của nhân tố môi trường pháp lý, cụ thể những văn bản quy định của pháp luật, những chế độ chính sách và chuẩn mực do nhà nước ban hành có sự tác động trực tiếp đến của kế toán tại các doanh nghiệp. Nếu môi trường pháp lý tốt, hướng dẫn đầy đủ, rõ ràng người làm kế toán sẽ hạn chế được các sai sót trong quá trình thực hiện công việc kế toán.

\subsubsection{Lý thuyết thông tin bất cân xứng}

Lý thuyết thông tin bất cân xứng được xuất hiện vào những năm 1970 và được ứng dụng rất nhiều trong các nghiên cứu. Nghiên cứu của Löfgren và cộng sự (2002) đã phân tích sự đóng góp lý thuyết thông tin bất cân xứng của nhóm tác giả George Akerlof, Michael Spence và Joseph Stiglitz. Cụ thể, thông tin bất cân xứng là một đặc điểm chung của các tương tác thị trường. Người bán hàng hóa thường biết nhiều về chất lượng của hàng hóa hơn là người mua tiềm năng. Người mua hợp đồng bảo hiểm thường biết nhiều về rủi ro cá nhân của mình hơn là công ty bảo hiểm. Vậy vấn đề đặt ra những người ít thông tin hơn cần làm gì để khắc phục điều này. Phương pháp đề xuất của George Akerlof, Michael Spence và Joseph Stiglitz đã 
giải quyết các vấn đề này. Như các công ty bảo hiểm có thể sàng lọc qua hợp đồng lựa chọn, bằng cách đưa ra các chính sách khác khau đối với từng nhóm nhóm khách hàng.

Lý thuyết này được ứng dụng rất nhiều trong nghiên cứu như về thông tin bất cân xứng giữa người sử dụng thông tin bên ngoài doanh nghiệp và nhà quản lý trong việc công bố thông tin (Lopatta và cộng sự (2016), Chaney và cộng sự (1995),...). Do yếu tố này tác động cho nên cần thiết phải có sự tác động của quản lý nhà nước trong việc đưa ra các quy định để bảo vệ quyền lợi của người sử dụng thông tin kế toán.

Qua nghiên cứu lý thuyết cho thấy rằng nếu nhà quản lý có nhận thức về kế toán sẽ làm giảm các sai sót có thể xảy ra trong công tác kế toán. Cụ thể hiện nay đối với các doanh nghiệp Việt Nam có quy mô nhỏ và vừa, công tác quản lý thông thường được chủ sở hữu tham gia, những doanh nghiệp này không tổ chức bộ phận kiểm toán nội bộ cũng như thuê các công ty kiểm toán độc lập từ bên ngoài vào để kiểm tra công tác kế toán. Cho nên các thông tin do kế toán cung cấp có thể xảy ra sai sót hoặc gian lận, do đó nếu nhà quản lý doanh nghiệp có sự hiểu biết về kế toán, tham gia vào việc tổ chức công tác kế toán trong doanh nghiệp, đọc hiểu thông tin được trình bày trên $\mathrm{BCTC}$ thì sẽ làm giảm thiểu các sai sót có thể xảy ra trong công tác kế toán.

\subsection{Các nhân tố ảnh hưởng đến sai sót trên BCTC}

\subsubsection{Năng lực kế toán viên}

Theo nghiên cứu của Busuioceanu Steliana (2013) đã chỉ ra được các hành vi dẫn đến sai sót liên quan đến năng lực chuyên môn của kế toán viên như hạch toán sai tài khoản; nhầm lẫn giữa các hoạt động kinh tế; ghi chép nghiệp vụ kinh tế. Còn nghiên cứu của Costi và Coman (2017) cho rằng những sai sót mà năng lực chuyên môn tác động đến là sai sót do diễn giải các sự kiện. Cũng theo nghiên cứu của Nguyễn Công Phương, cùng các cộng sự (2018) đã chỉ ra rằng ngoài sai sót có dấu hiện gian lận (báo cáo doanh thu, lợi nhuận cao, chi phí thấp, giá trị tài sản cao, nợ thấp), sai sót theo chiều hướng ngược lại cũng đáng kể ở tất cả các khía cạnh, dạng sai sót này thường được cho là nhầm lẫn. Điều này, đặt ra vấn đề về trình độ kế toán của các công ty niềm yết. Nguyễn Đình Tuấn (2017) thì cho rằng kế toán viên có nghiệp vụ năng lực yếu kém sẽ cung cấp thông tin kế toán có độ tin cậy không cao. Trong nghiên cứu của Trần Thị Yến và cộng sự (2017) đã chỉ ra rằng năng lực nhân viên kế toán tương thích với chất lượng $\mathrm{BCTC}$ theo hướng nhân viên kế toán có tinh thần ham học hỏi và cầu tiến; trình độ sử dụng công nghệ thông tin; số năm kinh nghiệm làm kế toán tại đơn vị càng cao sẽ làm tăng chất lượng BCTC.

Như vậy, con người là nhân tố chủ động tạo nên thông tin, con người có trình độ văn hóa, kỹ năng và năng lực nghiệp vụ về chuyên ngành kế toán, thuế sẽ đưa ra cách thông tin với chất lượng cao, đáp ứng được nhu cầu của các đối tượng sử dụng thông tin kế toán. Con người chính là chủ thể của hành vi sai sót, việc kế toán viên có năng lực nghiệp vụ sẽ hạn chế, giảm thiểu các sai sót xảy ra trong quá trình thực hiện công tác kế toán.

\subsubsection{Môi truờng pháp lý}

Ngày nay, kế toán là công cụ quản lý kinh tế, có chức năng thông tin và kiểm tra các hoạt động trong doanh nghiệp. Tổ chức công tác kế toán chịu ảnh hưởng rất lớn từ những quy định chung mang tính pháp lý: Luật kể toán, Chế độ kế toán, Chuẩn mực kế toán và các thông tư hướng dẫn quy định về kế toán. Việc tuân thủ chuẩn mực kế toán, áp dụng chính sách nhất quán, phù hợp và được trình bày theo khuôn khổ quy định của pháp luật là điều rất quan trọng sẽ giúp cho người lập và người sử dụng báo cáo tài chính hiểu được những thông tin ghi trên bản báo cáo, giúp báo cáo tài chính được trình bày trung thực và hợp lý, hạn chế được những sai sót có thể xảy ra. Trong nghiên cứu của Costi và Coman (2017) đã cho thấy việc áp dụng sai chính sách đã làm sai sót trên Báo cáo tài chính. Nghiên cứu của Hongjiang Xu cùng các cộng sự (2003) cũng đã khẳng định rằng việc thay đổi chính sách pháp luật cũng tác động tới hệ thống, chất lượng thông tin trên BCTC.

Như vậy, môi trường pháp lý có ảnh hưởng sâu sắc đến sai sót của kế toán viên từ đó ảnh hưởng đến chất lượng thông tin trên BCTC, đồng thời thông qua Chuẩn mực và các chính sách, quy định của pháp luật này thì cơ quan nhà nước góp phần điều chỉnh, hạn chế sai sót của kế toán viên nói riêng và sai sót đến chất lượng thông tin BCTC nói chung.

\subsubsection{Năng lực nhà lãnh đạo}

Trong nghiên cứu của Hongjiang Xu cùng các cộng sự (2003) và nghiên cứu của Caster và cộng sự (2000) đã cho thấy rằng yếu tố nhà lãnh đạo có ảnh hưởng đến các sai sót của kế toán viên từ đó ảnh hưởng đến 
chất lượng thông tin trên BCTC. Trong nghiên cứu của Nguyễn Công Phương và cộng sự (2018) khẳng định rằng sai sót của kế toán viên một phần là do yếu tố nội tại công ty như quản lý điều hành, quản trị công ty tạo áp lực lên kế toán viên. Còn theo Trần Thị Yến và Hoàng Thị Thúy (2017) việc nhà lãnh đạo quan tâm đến hoạt động kế toán của đơn vị và hiểu biết về kế toán cũng sẽ giúp cho BCTC khi được công bố có độ tin cậy cao.

\subsubsection{Hệ thống kiểm soát nội bộ}

Theo nghiên cứu của Trần Thị Yến và cộng sự (2017) hệ thống kiểm soát nội bộ là một nhân tố quan trọng tác động đến chất lượng BCTC. Việc thiết lập hệ thống kiểm soát nội bộ tốt, sẽ hỗ trợ các đơn vị kiểm soát được việc chấp hành các quy định pháp luật về kế toán, giảm thiểu các sai sót và rủi ro có ảnh hưởng công tác kế toán tại đơn vị.

Như vậy, hệ thống kiểm soát nội bộ là một công cụ hữu hiệu trong việc kiểm tra, phát hiện và ngăn ngừa sai sót đảm bảo việc lập báo cáo tài chính một cách trung thực và chính xác. Qua đó, việc tuân thủ các chế độ, các quy định mà trong đó có tuân thủ pháp luật lệ về thuế được thực hiện.

\subsection{5 Úng dụng công nghệ thông tin}

Trong Hệ thống thông tin Kế toán của Nguyễn Thế Hưng (2008) cho rằng, hệ thống thông tin gồm 3 thành phần cơ bản, bao gồm: Các yếu tố đầu vào, xử lý, các yếu tố đầu ra. Hệ thống thông tin kế toán (AIS) thông qua việc thu thập dữ liệu của các hoạt động trong năm sẽ cung cấp các thông tin hữu ích để tạo điều kiện cho quá trình ra quyết định của nhà quản lý. Hệ thống thông tin kế toán phải linh hoạt để đáp ứng kịp thời và đầy đủ các thông tin khác nhau từ các nhà quản lý. Không chỉ thế, thông tin từ AIS cũng rất cần thiết cho các đối tượng bên ngoài doanh nghiệp dưới dạng các báo cáo tài chính, báo cáo thuế,...

Cũng trong nghiên cứu của $\mathrm{Ngô}$ Thi Thu Hằng và cộng sự (2013) nghiên cứu về những yếu tố trong hệ thống thông tin kế toán có tác động đến gian lận và sai sót thì tác giả cũng chỉ ra rằng mức độ ứng dụng công nghệ thông tin trong công tác kế toán có ả̉nh hưởng rất lớn trong việc hạn chế các gian lận và sai sót có thể xảy ra.

Ngày nay, sự phát triển của khoa học, kỹ thuật và công nghệ thông tin được ứng dụng nhiều vào các lĩnh vực hoạt động của con người cũng như trong lĩnh vực quản lý. Điều đó đòi hỏi các doanh nghiệp phải ứng dụng công nghệ thông tin vào việc tổ chức thực hiện công tác kế toán nhằm tạo ra một hệ thống thông tin kể toán hợp lý, được kiểm soát chặt chẽ, cung cấp thông tin trung thực, đáng tỉn cậy với những kỹ thuật xử lý thông tin kế toán mới, góp phần vào việc giảm thiểu sai sót về chất lượng thông tin trên BCTC.

\subsubsection{Kế hoạch đào tạo và bồi duõng}

Theo nghiên cứu của Phạm Quốc Thuần (2016) cho rằng các doanh nghiệp nên chú trọng đến việc đào tạo và cập nhật kiến thức thường xuyên cho nhân viên kế toán. Doanh nghiệp đã tạo nhiều điều kiện thuận lợi về nguồn lực và tài chính để đảm bảo chất lượng công việc cũng như đảm bảo cho nhân viên kế toán được bồi dưỡng thường xuyên kiến thức góp phần gia tăng chất lượng thông tin trên Báo cáo tài chính. Qua đó, có thể thấy kế hoạch đào tạo và bồi dưỡng là nhân tố có ảnh hưởng đến sai sót trên báo cáo tài chính của các doanh nghiệp.

\section{XÂY DỰNG GIẢ THUYẾT VÀ MÔ HİNH NGHIÊN CỨU}

Từ lý thuyết và các nghiên cứu có liên quan, đồng thời phỏng vấn các chuyên gia trong lĩnh vực kế toán, giả thuyết được xây dựng như sau:

Giả thuyết H1: Nhân tố "Môi trường pháp lý” có tác động tích cực làm giảm sai sót trong kế toán

Giả thuyết H2: Nhân tố "Úng dụng công nghệ thông tin" có tác động tích cực làm giảm sai sót trong kế toán

Giả thuyết H3: Nhân tố "Năng lực kế toán viên" có tác động tích cực làm giảm sai sót trong kế toán

Giả thuyết H4: Nhân tố "Hệ thống kiểm soát nội bộ" có tác động tích cực làm giảm sai sót trong kế toán

Giả thuyết H5: Nhân tố "Năng lực và nhận thức nhà lãnh đạo" có tác động tích cực làm giảm sai sót trong kế toán

Giả thuyết H6: Nhân tố "Kế hoạch đào tạo và bồi dưỡng" có tác động tích cực làm giảm sai sót trong kế toán 


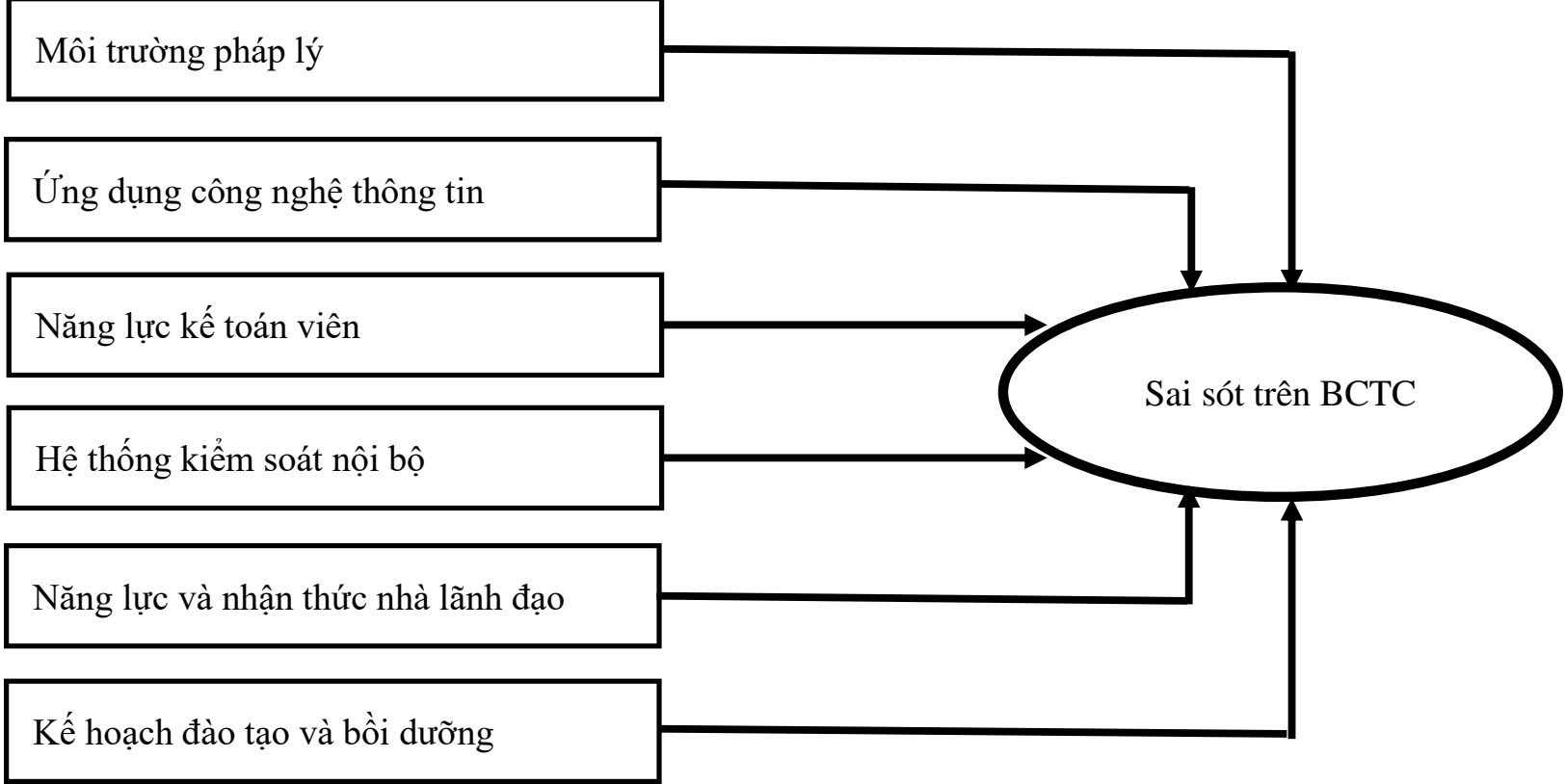

Hình 1: Mô hình nghiên cúu

Mô hình hồi quy đề xuất kiểm định giả thuyết như sau:

(Nguồn: Tác giả tụ tổng hợp) $\mathrm{SSBC}=\beta 1 * \mathrm{MTPL}+\beta 2 * \mathrm{CNTT}+\beta 3 * \mathrm{NLKT}+\beta 4 * \mathrm{KSNB}+\beta 5 * \mathrm{NLLD}+\beta 6 * \mathrm{DTBD}+\varepsilon$

Trong đó, các biến độc lập: MTPL: Môi trường pháp lý; CNTT: Ứng dụng công nghệ thông tin; NLKT: Năng lực kế toán viên; KSNB: Hệ thống kiểm soát nội bộ; NLLD: Năng lực và nhận thức nhà lãnh đạo; DTBD: Kế hoạch đào tạo bồi dưỡng; Biến phụ thuộc: SSBC: Sai sót trên BCTC

$\varepsilon$ : Hệ số nhiễu

$\beta 1, \beta 2, \beta 3, \ldots$ : hệ số hồi qui chuẩn hóa

\section{PHƯƠNG PHÁP NGHIÊN CÚU}

\subsection{Mẫu khảo sát:}

Dữ liệu thu thập bằng cách gửi bảng câu hỏi những người đang làm kế toán, kiểm toán tại các doanh nghiệp và các chuyên gia làm trong lĩnh vực kế toán, kiểm toán trên địa bàn TP HCM. Bảng câu hỏi thiết kế sẳn gồm thông tin người trả lời và 26 câu hỏi cho các biến độc lập và 3 câu hỏi cho biến phụ thuộc theo mô hình nghiên cứu bao gồm 2 loại câu hỏi như sau: (i) Sử dụng thang đó Likert để đánh giá mức ảnh hưởng, gồm 5 mức ảnh hưởng: (1) Rất không đồng ý; (2) Không đồng ý; (3) Phân vân; (4) Đồng ý; (5) Rất đồng ý. (ii) Loại câu hỏi mở: Đối với loại câu hỏi này, tác giả sử dụng dạng câu hỏi mở để người tham gia khảo sát có thể đưa ra ý kiến hoặc bổ sung thêm các thang đo.

Số lượng phiếu phát ra là 200 phiếu khảo sát, số phiếu thu lại gồm 175 phiếu, trong quá trình nhập liệu và làm sạch số liệu có 150 phiếu trả lời hợp lệ.

Theo Hair và cộng sự (2013), trong phân tích nhân tố khám phá thì số quan sát (cỡ mẫu) ít nhất phải bằng 5 lần số biến. Mô hình nghiên cứu này có 29 biến quan sát, nên số lượng tối thiểu là: $n=5 * 29=145$. Như vậy, số lượng 150 bảng câu hỏi là phù hợp với nghiên cứu này.

Theo Tabachnick \& Fidell (2007) cỡ mẩu dùng cho phân tích hồi quy được xác định $n>=50+5 p$ (trong đó $\mathrm{p}$ là số biến độc lập. Như vậy số mẫu tối thiểu của bài nghiên cứu là $\mathrm{n}=50+8 * 6=98$. Nghiên cứu sử dụng kích thước mẫu là $n=150$, do đó kích thước mẫu này hoàn toàn phù hợp cho nghiên cứu.

\subsection{Phương pháp nghiên cứu}

Bài nghiên cứu "Nhân tố ảnh hưởng đến sai sót trên BCTC của doanh nghiệp nhỏ và vừa" được hoàn thành dựa trên quá trình nghiên cứu khoa học và rõ ràng.

Trước tiên, nhóm nghiên cứu đã tìm hiểu các lý thuyết về sai sót và những ảnh hưởng đến sai sót trên Báo cáo tài chính. Bên cạnh đó, nhóm đã tiến hành thu thập từ các công trình nghiên cứu trước đây của trong 
nước và nước ngoài về những nhân tố ảnh hưởng đến sai sót báo cáo tài chính bằng phương pháp định tính để làm cơ sở lý luận cho bài nghiên cứu. Tiếp theo nhóm nghiên cứu đã xây dựng được thang đo nháp, đây là bước đầu tiên nhưng rất quan trọng giúp xác định đúng, rõ ràng vấn đề nghiên cứu.

Từ thang đo nháp, nhóm tiến hành phỏng vấn, thảo luận lấy ý kiến của các chuyên gia, và các kế toán trưởng tại các doanh nghiệp. Sau đó điều chỉnh, thiết kế thang đo cho các nhân tố làm cơ sở để hoàn thiện bảng câu hỏi chính thức.

Ngoài ra, nhóm nghiên cứu sử dụng phương pháp định lượng nhằm tạo ra quy trình phân tích định lượng chặt chẽ. Bao gồm thực hiện các kiểm định Cronbach's Alpha để kiểm định độ tị cậy của thang đo, kiểm định phân tích nhân tố khám phá (EFA-Exploratory Factor Analysis) đối với các giả thuyết và sự phù hợp của mô hình, cuối cùng phân tích hồi quy để tìm ra mức độ ảnh hưởng của các nhân tố đến sai sót.

\subsection{Thang đo các khái niệm trong mô hình nghiên cứu}

Từ kết quả phỏng vấn các chuyên gia và mô hình nghiên cứu dự kiến, nhóm nghiên cứu đã điều chỉnh lại mô hình nghiên cứu và xây dựng các thang đo như sau:

Môi truoòng pháp lý Dựa trên nghiên cứu của Costi và Coman (2017), Nguyễn Đình Tuấn (2016), khảo sát ý kiến chuyên gia. Môi trường pháp lý đo lường thông qua các biến quan sát có ký hiệu MTPL: (i) MTPL1: Thông tư hướng dẫn thực hiện công tác kế toán quy định rõ ràng; MTPL2: Chuẩn mực, chế độ kế toán quy định đầy đủ, kịp thời các vấn đề phát sinh trong thực tế tại doanh nghiệp; MTPL3: Thu hẹp khoảng cách giữa thuế và kế toán; MTPL4: Các quy định trong Luật, chế độ, thông tư hướng dẫn về kế toán được ban hành thống nhất, không có sự khác biệt.

Úng dụng công nghệ thông tin Tổng hợp từ nghiên cứu Nguyễn Đình Tuấn (2016), Phạm Quốc Thuần (2016). Ửng dụng công nghệ thông tin đo lường thông qua các biến quan sát có ký hiệu CNTT: (i) CNTT1: Cơ sở hạ tầng đầy đủ đáp ứng yêu cầu ứng dụng công nghệ thông tin trong công tác kế toán; (ii) CNTT2: Doanh nghiệp có sử dụng phần mềm trong thực hiện công tác kế toán; (iii) CNTT3: Phần mềm kế toán được cập nhật, nâng cấp thường xuyên; (iv) CNTT4: Phần mềm dễ sử dụng và được hướng dẫn sử dụng đầy đủ; (v) CNTT5: Phần mềm đáp ứng đầy đủ các nghiệp vụ kế toán của doanh nghiệp.

Năng lực kế toán viên Qua tổng hợp nghiên cứu của Busuioceanu Steliana (2013), Costi và Coman (2017), Nguyễn Công Phương, cùng các cộng sự (2018), Phạm Quốc Thuần (2016), Nguyễn Đình Tuấn (2017), ý kiến chuyên gia. Năng lực kế toán viên đo lường thông qua các biến quan sát có ký hiệu NLKT: (i) NLKT1: Kế toán viên áp dụng đúng các quy định về kế toán vào thực tế công việc tại doanh nghiệp; (ii) NLKT2: Kế toán viên có các kỹ năng sử dụng phần mềm kế toán; (iii) NLKT3: Kế toán viên có khả năng tự học, tự nghiên cứu; (iv) NLKT4: Kế toán viên luôn cập nhật quy định mới quy định mới về kế toán; (v) NLKT5: Kế toán viên áp dụng chính sách kế toán phù hợp với đặc thù của doanh nghiệp.

Hệ thống kiểm soát nội bộ Trên cơ sở các nghiên cứu của Phạm Quốc Thuần (2016), Nguyễn Đình Tuấn (2016), Trần Thị Yến và cộng sự (2017), ý kiến chuyên gia. Hệ thống kiểm soát nội bộ đo lường thông qua các biến quan sát có ký hiệu KSNB: (i) KSNB1: Các hoạt động kiểm soát được quy định bằng văn bản; (ii) KSNB2: Thực hiện kiểm tra, giám sát thường xuyên và đối chiếu giữa các bộ phận; (iii) KSNB3: Sắp xếp, bố trí người làm kế toán phù hợp với năng lực của họ; (iv) KSNB4: Việc phân công công việc trùng lặp do ít nhân viên làm tăng nguy cơ sai sót tại doanh nghiệp; (v) KSNB5: Có sự tham gia chủ sở hữu có chuyên môn vào việc quản lý các nghiệp vụ hàng ngày.

Năng lực và nhận thức nhà lãnh đạo Dựa vào nghiên cứu của Phạm Quốc Thuần (2016), Hongjiang Xu cùng các cộng sự (2003), Paul Caster và cộng sự (2000), Nguyễn Công Phương cùng các cộng sự (2018). Năng lực và nhận thức nhà lãnh đạo đo lường thông qua các biến quan sát có ký hiệu NLLD: (i) NLLD1: Sự truyền đạt thông tin rõ ràng của lãnh đạo đển nhân viên kế toán; (ii) NLLD2: Nhà lãnh đạo thường xuyên quan tâm đến tổ chức, vận hành công tác kế toán; (iii) NLLD3: Nhà lãnh đạo có sự am hiểu về kế toán; (iv) NLLD4: Lắng nghe ý kiến của nhân viên giúp nhà lãnh đạo cải thiện môi trường làm việc.

Kế hoạch đào tạo và bồi duoõng Tổng hợp từ nghiên cứu Phạm Quốc Thuần (2016). Kế hoạch đào tạo và bồi dưỡng đo lường thông qua các biến quan sát có ký hiệu DTBD: (i) DTBD1: Đơn vị luôn yêu cầu nhân viên phải luôn nâng cao trình độ về kế toán và thuế; (ii) DTBD2: Đơn vị có kế hoạch đào tạo định kỳ kiến thức kế toán và thuế cho nhân viên; (iii) DTBD3: Đơn vị tạo điều kiện về mặt thời gian và chi phí để hỗ trợ nhân viên nâng cao kiến thức chuyên.

Nhân tố phụ thuộc 
Để đo lường cho biến phụ thuộc, căn cứ để xây dựng thang do này dựa vào VAS 21, VAS 29 nghiên cứu thiết kế các biến quan sát như sau:

Bảng 2: Thang đo biến phụ thuộc.

\begin{tabular}{|c|l|}
\hline \multicolumn{2}{|c|}{ Thang đo giảm thiểu sai sót trên BCTC của các doanh nghiệp nhỏ và vừa tại TP.Hồ Chí Minh } \\
\hline Mã & \multicolumn{1}{c|}{ Biến quan sát } \\
\hline SSBC1 & Thông tin trên báo cáo tài chính được phản ánh đúng bản chất kinh tế của các giao dịch và sự kiện \\
\hline SSBC2 & Cung cấp thông tin hữu ích cho người sử dung \\
\hline SSBC3 & Thông tin trên $B C T C$ được trình bày trung thực hợp lý trên các khía cạnh trọng yếu \\
\hline
\end{tabular}

\section{KẾT QUẢ VÀ THẢO LUẬn}

Nguồn: Nhóm nghiên cứu tổng hợp

\subsection{Kết quả khảo sát thống kê mô tả}

Đối tượng chọn mẫu là những người đang làm kế toán, kiểm toán tại các doanh nghiệp và các chuyên gia làm trong lĩnh vực kế toán, kiểm toán trên. Đặc điểm mẫu khảo sát như sau:

Bảng 3: Đặc điểm mẫu nghiên cứu

\begin{tabular}{|c|c|c|c|c|c|c|c|c|c|c|c|c|c|c|}
\hline \multicolumn{2}{|c|}{ Giới tính } & \multicolumn{3}{|c|}{ Chuyên ngành } & \multicolumn{3}{|c|}{ Vị trí công tác } & \multicolumn{4}{|c|}{ Mức lương } & \multicolumn{3}{|c|}{ Kinh nghiệm } \\
\hline Nam & Nũ̃ & $\begin{array}{l}\text { Kế } \\
\text { toán }\end{array}$ & $\begin{array}{l}\text { Kiểm } \\
\text { toán }\end{array}$ & Khác & $\begin{array}{l}\text { Kế } \\
\text { toán }\end{array}$ & $\begin{array}{l}\text { Kiểm } \\
\text { toán }\end{array}$ & Khác & $\begin{array}{c}\text { Từ } 5 \\
\text { đến } \\
10 \\
\text { triệu }\end{array}$ & $\begin{array}{c}\text { Từ } \\
10 \\
\text { đến } \\
15 \\
\text { triệu }\end{array}$ & $\begin{array}{c}\text { Từ } \\
15 \\
\text { đến } \\
20 \\
\text { triệu }\end{array}$ & $\begin{array}{c}\text { Trên } \\
20 \\
\text { triệu }\end{array}$ & $\begin{array}{c}\text { Dưới } \\
5 \\
\text { năm }\end{array}$ & $\begin{array}{c}\text { Từ } 5 \\
\text { năm } \\
\text { dến } \\
10 \\
\text { năm }\end{array}$ & $\begin{array}{c}\text { Trên } \\
10 \\
\text { năm }\end{array}$ \\
\hline $18 \%$ & $82 \%$ & $89 \%$ & $3 \%$ & $8 \%$ & $93 \%$ & $3 \%$ & $4 \%$ & $24 \%$ & $41 \%$ & $23 \%$ & $12 \%$ & $41 \%$ & $38 \%$ & $21 \%$ \\
\hline
\end{tabular}

(Nguồn: Phân tích dũ liệu SPSS)

Kết quả thông kê mô tả (Bảng 4) cho thấy hầu hết các biến quan sát của nhân tố phụ thuộc đều $>3$. Chứng tỏ rằng, các biến quan sát được rút ra từ nghiên cứu định tính đều được các đối tượng khảo sát đồng ý.

Bảng 4: Thống kê mô tả các biến đưa vào mô hình

\begin{tabular}{|l|r|c|c|}
\hline \multicolumn{1}{|c|}{ Tên biến } & \multicolumn{1}{c|}{ N } & Giá trị Trung Bình & Độ lệch chuẩn \\
\hline MTPL & 150 & 3,628 & 0,890 \\
\hline CNTT & 150 & 3,692 & 0,830 \\
\hline NLKT & 150 & 4,236 & 0,878 \\
\hline KSNB & 150 & 3,794 & 0,919 \\
\hline NLLD & 150 & 3,858 & 0,911 \\
\hline DTBD & 150 & 3,513 & 0,880 \\
\hline SSBC & 150 & 3,783 & 0,687 \\
\hline
\end{tabular}

\subsection{Kết quả kiểm định thang đo}

Nguồn: Nhóm nghiên cứu tổng hợp

Bài nghiên cứu tiến hành kiểm định Cronbach's Alpha các nhóm nhân tố tác động đến sai sót trên Báo cáo tài chính của các doanh nghệp vừa và nhỏ với 6 nhóm (26 biến độc lập) và 1 nhóm ( 3 biến phụ thuộc). Kết quả kiểm định Cronbach's Alpha cuối cùng của từng nhân tố được tổng hợp trong bảng 5 . Sau khi kiểm định độ tin cậy Cronbach's Alpha, loại biến KSNB5 do Corrected Item-Total Correlation nhỏ hơn 0.3, tiến hành chạy lại lần 2. Các biến còn lại có hệ số Cronbach's Alpha đều $>0,6$ và hệ số tương quan với biến tổng của các nhân tố đều $>0,3$. Chứng tỏ thang đo đảm bảo độ tin cậy và thích hợp đưa vào phân tích ở bước tiếp theo.

Như vậy, sau khi kiểm định bằng hệ số Cronbach's Alpha thì còn 28 biến quan sát phù hợp, các biến này tiếp tục tiến hành phân tích EFA để kiểm tra mức độ tin cậy (biến KSNB5 đã loại không được đưa vào chạy EFA) trong bước tiếp theo. 
CÁC DOANH NGHIỆP NHỎ VÀ VỪA

Bảng 5: Kiểm định thang đo bằng hệ số tin cậy Cronbach's Alpha

\begin{tabular}{|c|l|c|}
\hline STT & \multicolumn{1}{|c|}{ Thang đo } & Hệ số Cronbach's Alpha \\
\hline 1 & Môi trường pháp lý (MTPL) & 0.812 \\
\hline 2 & Hệ thống thông tin kế toán (CNTT) & 0.827 \\
\hline 3 & Năng lực kế toán viên (NLKT) & 0.811 \\
\hline 4 & Hệ thống kiểm soát nội bộ (KSNB) & 0.801 \\
\hline 5 & Năng lực và nhận thức nhà lãnh đạo (NLLD) & 0.788 \\
\hline 6 & Kế hoạch đào tạo và bồi dưỡng (DTBD) & 0.722 \\
\hline 7 & Sai sót Báo cáo tài chính (SSBC) & 0.756 \\
\hline
\end{tabular}

\section{3 Đánh giá giá trị thang đo - phân tích nhân tố khám phá EFA}

(Nguồn: Phân tích dũ liệu SPSS)

Kết quả kiểm tra độ tin cậy thông qua hệ số Cronbach's alpha cho thấy 26 biến (biến độc độc lâp) quan sát của thang đo các nhân tố ảnh hưởng đến sai sót trên $\mathrm{BCTC}$ của các doanh nghiệp nhỏ và vừa đạt yêu cầu sẽ được đưa vào phân tích nhân tố EFA.

Bảng 6: Kết quả phân tích nhân tố biến độc lập

\begin{tabular}{|l|c|}
\hline \multicolumn{1}{|c|}{ Nhân tố đánh giá } & Giá trị kiểm định \\
\hline Hệ số KMO & 0.826 \\
\hline Giá trị Sig. trong kiểm định Barlett's & 0.000 \\
\hline Tổng phương sai trích & $63.825 \%$ \\
\hline Hệ số Eigenvalues & 1.377 \\
\hline
\end{tabular}

(Nguồn: Phân tích dữ liệu SPSS)

Kết quả kiểm định Barlett cho thấy giữa các biến trong tổng thể có mối tương quan với nhau (sig $=0.000$ $<0.05$ ). Đồng thời, hệ số $\mathrm{KMO}=0.826>0.5$, chứng tỏ phân tích nhân tố để nhóm các biến lại với nhau là thích hợp và dữ liệu phù hợp cho việc phân tích nhân tố.

Hệ số Eigenvalues $=1.377>1$ tại nhân tố thứ 6 , như vậy 6 nhân tố rút trích được từ EFA có ý ghĩa tóm tắt thông tin các biến quan sát đưa vào tốt nhất. Tổng phương sai trích: Rotation Sums of Squared Loadings $($ Cumulative $\%)=63.825 \%>50 \%$. Điều này chứng tỏ $63.825 \%$ biến thiên của dữ liệu được giải thích bởi 6 nhân tố.

Theo bảng 7 , phương sai trích đạt $63.825 \%$, vì yêu cầu hệ số tải nhân tố (factor loading) của các biến $(>0.5)$, nên tất cả các biến đều đạt yêu cầu.

Phương pháp trích nhân tố chính, phép xoay varimax để xoay nhân tố: xoay nguyên góc nhân tố để tối thiểu hóa số lượng biến có hệ số lớn tại cùng một nhân tố, vì vậy sẽ tăng cường khả năng giải thích nhân tố.

Bảng 7: Kết quả phẩn tích EFA

\begin{tabular}{|c|c|c|c|c|c|c|}
\hline & & & Nhâ & & & \\
\hline & 1 & 2 & 3 & 4 & 5 & 6 \\
\hline NLKT2 & .789 & & & & & \\
\hline NLKT1 & .743 & & & & & \\
\hline NLKT5 & .735 & & & & & \\
\hline NLKT3 & .707 & & & & & \\
\hline NLKT4 & .603 & & & & & \\
\hline MTPL2 & & .790 & & & & \\
\hline MTPL4 & & .767 & & & & \\
\hline MTPL3 & & .758 & & & & \\
\hline MTPL1 & & .752 & & & & \\
\hline NLLD4 & & & .787 & & & \\
\hline NLLD1 & & & .748 & & & \\
\hline NLLD3 & & & .725 & & & \\
\hline NLLD2 & & & .665 & & & \\
\hline
\end{tabular}




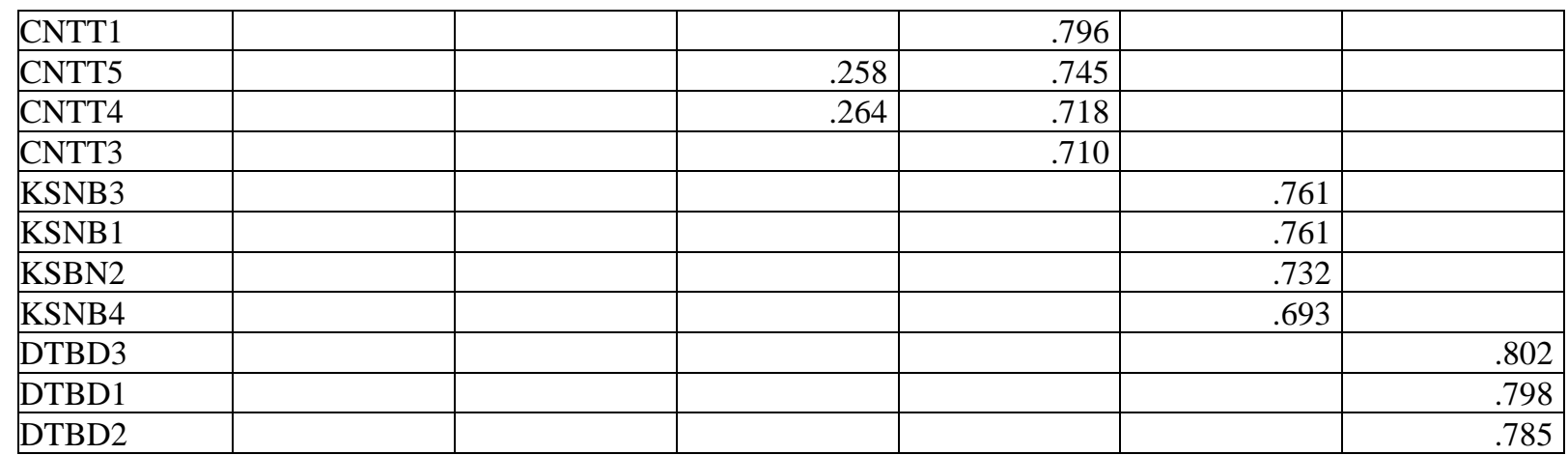

(Nguồn: Phân tích dữ liệu SPSS)

Giá trị ma trận của biến phụ thuộc SSBC

Bảng 8: Bảng ma trận của biến phụ thuộc

\begin{tabular}{|l|r|}
\hline \multicolumn{1}{|c|}{ Biến quan sát } & \multicolumn{2}{c|}{ Nhân tố } \\
\hline SSBC3 & .827 \\
\hline SSBC2 & .825 \\
\hline SSBC1 & .810 \\
\hline
\end{tabular}

(Nguồn: Phân tích dữ liệu SPSS)

Theo số liệu của bảng 8 cho thấy giá trị của biến Y khá lớn $(>50 \%)$ do đó dữ liệu thu thập là phù hợp với việc rút trích các nhân tố và có thể sử dụng cho các bước phân tích hồi quy tiếp theo.

\subsection{Kiểm định sự phù hợp của mô hình nghiên cứu}

Sau khi đã có được các biến đại diện độc lập và phụ thuộc ở phần phân tích nhân tố $\mathrm{EFA}$, nhóm nghiên cứu tiến hành phân tích tương quan Pearson để kiểm tra mối quan hệ tuyến tính giữa các biến này. Phân tích tương quan hệ số được thực hiện trước khi tiến hành phân tích hồi quy đa biến.

Theo bảng 9, Sig tương quan Pearson các biến độc lập MTPL, CNTT, NLKT, KSNB, NLLD, DTBD với biến phụ thuộc SSBC nhỏ hơn 0.05 . Như vậy, có mối liên hệ tuyến tính giữa các biến độc lập với biến SSBC. Giữa NLKT và SSBC có mối tương quan mạnh nhất với hệ số $\mathrm{r}$ là 0.621 , giữa $\mathrm{MTPL}$ và $\mathrm{DTBD}$ có mối tương quan yếu nhất với hệ số $\mathrm{r}$ là 0.143 .

Bảng 9: Bảng phương sai trích

\begin{tabular}{|c|c|c|c|c|c|c|c|c|}
\hline & & SSBC & NLKT & KSNB & MTPL & CNTT & NLLD & DTBD \\
\hline \multirow{7}{*}{ Pearson Correlation } & SSBC & 1 & $.621^{* *}$ & $.613^{* *}$ & $.529^{* *}$ & $.522^{* *}$ & $.499^{* *}$ & $.424^{* *}$ \\
\hline & NLKT & $.621^{* *}$ & 1 & $.457^{* *}$ & $.289^{* *}$ & $.262^{* *}$ & $.339^{* *}$ & $.281^{* *}$ \\
\hline & KSNB & $.613^{* *}$ & $.457^{* *}$ & 1 & $.362^{* *}$ & $.311^{* *}$ & $.338^{* *}$ & $.293^{* *}$ \\
\hline & MTPL & $.529^{* *}$ & $.289^{* *}$ & $.362^{* *}$ & 1 & $.324^{* *}$ & $.243^{* *}$ & .143 \\
\hline & CNTT & $.522^{* *}$ & $.262^{* *}$ & $.311^{* *}$ & $.324^{* *}$ & 1 & $.416^{* *}$ & $.246^{* *}$ \\
\hline & NLLD & $.499^{* * *}$ & $.339^{* *}$ & $.338^{* *}$ & $.243^{* *}$ & $.416^{* *}$ & 1 & $.355^{* *}$ \\
\hline & DTBD & $.424^{* *}$ & $.281^{* *}$ & $.293^{* *}$ & .143 & $.246^{* *}$ & $.355^{* *}$ & 1 \\
\hline \multirow{7}{*}{$\begin{array}{c}\text { Sig. } \\
\text { (1-tailed) }\end{array}$} & SSBC & & .000 & .000 & .000 & .000 & .000 & .000 \\
\hline & NLKT & .000 & & .000 & .000 & .001 & .000 & .000 \\
\hline & KSNB & .000 & .000 & & .000 & .000 & .000 & .000 \\
\hline & MTPL & .000 & .000 & .000 & & .000 & .003 & .082 \\
\hline & CNTT & .000 & .001 & .000 & .000 & & .000 & .002 \\
\hline & NLLD & .000 & .000 & .000 & .003 & .000 & & .000 \\
\hline & DTBD & .000 & .000 & .000 & .082 & .002 & .000 & \\
\hline
\end{tabular}

(Nguồn: Phân tích dữ liệu SPSS) 


\subsection{Phân tích hồi quy đa biến}

Phân tích ANOVA là một kiểm định giả thuyết về độ phù hợp của mô hình hồi quy tuyến tính tổng thể.

Bảng 10: Kiểm định độ phù hợp của mô hình

\begin{tabular}{|c|c|c|c|c|c|c|}
\hline \multicolumn{2}{|c|}{ Mô hình } & $\begin{array}{c}\text { Tổng bình phương } \\
\text { (Sum of Squares) }\end{array}$ & Bậc tự do (df) & $\begin{array}{c}\text { Trung bình bình phương } \\
\text { (Mean Square) }\end{array}$ & $\mathrm{F}$ & Sig. \\
\hline \multirow{3}{*}{1} & Hồi quy & 32.721 & 6 & 5.454 & 53.259 & $.000^{\mathrm{b}}$ \\
\cline { 2 - 7 } & Phần dư & 14.643 & 143 & .102 & & \\
\cline { 2 - 7 } & Tổng & 47.364 & 149 & & & \\
\hline
\end{tabular}

(Nguồn: Phân tích dữ liệu SPSS)

Theo số liệu của bảng 10 cho thấy kết quả kiểm định ANOVA với Sig kiểm định $\mathrm{F}=0.00<0.05$, như vậy mô hình hồi quy có ý nghĩa và phù hợp với dữ liệu đã thu thập.

\subsection{Mô hình hồi quy tuyến tính bội}

Bảng 11: Thông số thống kê trong mô hình hồi quy

\begin{tabular}{|c|c|c|c|c|c|c|c|c|}
\hline \multirow{2}{*}{\multicolumn{2}{|c|}{ Mô hình }} & \multicolumn{2}{|c|}{ Hệ số chưa chuẩn hóa } & \multirow{3}{*}{\begin{tabular}{|c} 
Hệ số chuẩn \\
hóa
\end{tabular}} & \multirow{3}{*}{$\begin{array}{c}\mathbf{t} \\
-.563 \\
\end{array}$} & \multirow{3}{*}{$\begin{array}{l}\text { Sig. } \\
.574\end{array}$} & \multicolumn{2}{|c|}{ Thống kế đa cộng tuyến } \\
\hline & & \multirow{2}{*}{$\begin{array}{c}\mathbf{B} \\
-.125 \\
\end{array}$} & \multirow{2}{*}{$\begin{array}{c}\begin{array}{c}\text { Sai số } \\
\text { chuẩn }\end{array} \\
.222 \\
\end{array}$} & & & & Hê số & \\
\hline \multirow{7}{*}{1} & (Constant) & & & & & & & \\
\hline & KSNB & .199 & .046 & .241 & 4.292 & .000 & .688 & 1.453 \\
\hline & NLLD & .095 & .044 & .120 & 2.185 & .031 & .714 & 1.401 \\
\hline & MTPL & .188 & .041 & .238 & 4.591 & .000 & .806 & 1.241 \\
\hline & DTBD & .108 & .040 & .140 & 2.727 & .007 & .824 & 1.214 \\
\hline & NLKT & .262 & .046 & .308 & 5.666 & .000 & .730 & 1.371 \\
\hline & CNTT & .164 & .043 & .205 & 3.826 & .000 & .755 & 1.325 \\
\hline
\end{tabular}

(Nguồn: Phân tích dữ liệu SPSS)

Kết quả hồi quy cho thấy tất cả các biến (1) Hệ thống kiểm soát nội bộ, (2) Năng lực nhà lãnh đạo, (3) Môi trường pháp lý, (4) Kế hoạch đào tạo và bồi dưỡng, (5) Năng lực kế toán viên, (6) Hệ thống thông tin kế

$$
\mathrm{SSBC}=0,308 * \mathrm{NLKT}+0,241 * \mathrm{KSNB}+0,238 * \mathrm{MTPL}+0,205 * \mathrm{CNTT}+0,140 * \mathrm{DTBD}+0,120 * \mathrm{NLLD}
$$

có hiện tượng đa cộng tuyến xảy ra. Từ đó, ta có Phương trình hồi quy bội được thể dưới dạng mô hình hồi quy chuẩn hóa:

Như vậy, từ kết quả trên cho thấy 6 nhân tố gồm (1) Hệ thống kiểm soát nội bộ, (2) Năng lực nhà lãnh đạo, (3) Môi trường pháp lý, (4) Kế hoạch đào tạo và bồi dưỡng, (5) Năng lực kế toán viên, (6) Hệ thống thông tin kế toán đều tác động cùng chiều đến việc làm giảm sai sót sai sót trên BCTC. Trong đó, mức độ tác động của nhân tố Năng lực kế toán là cao nhất với $24,6 \%$, tiếp đến là nhân tố Hệ thống kiểm soát nội bộ với 19,2\% và các thứ tự tiếp theo là Môi trường pháp lý (19\%), Hệ thống thông tin kế toán $(16,4 \%)$, Kể hoạch đào tạo và bồi dưỡng $(11,2 \%)$, Năng lực và nhận thức nhà lãnh đạo $(9,6 \%)$. Tóm lại, giả thuyết $H 1$, H2, H3, H4, H5, H6 cho mô hình nghiên cứu lý thuyết chính thức được chấp nhận.

\section{KẾT LUẬN VÀ KIẾN NGH!}

Nghiên cứu này kiểm định các mối quan hệ giữa các nhân tố, trong đó có 6 nhân tố ảnh hưởng đến sai sót thông tin trên báo cáo tài chính của doanh nghiệp nhỏ và vừa gồm: (1) Môi trường pháp lý, (2) Ứng dụng công nghệ thông tin, (3) Năng lực kế toán viên, (4) Hệ thống kiểm soát nội bộ, (5) Năng lực nhà lãnh đạo, và (6) Kế hoạch đào tạo và bồi dưỡng. Đồng thời nghiên cứu đưa ra đề xuất một số kiến nghị nhằm hạn chế mức độ sai sót khi lập BCTC để tạo được lòng tin cho các bên sử dụng như sau:

\subsection{Năng lực kế toán viên}

Kế toán viên cần có ý thức việc tự học, tự nghiên cứu cũng như khả năng tìm hiểu và cập nhật kiến thức chuyên môn. Đặc biệt là trong xu thế Việt Nam đang chuẩn bị áp dụng IFRS (International Financial 
Reporting Standards) vào trong công việc kế toán, chuyển đổi BCTC theo IFRS. IFRS là chuẩn mực BCTC quốc tế vẫn còn rất mới tại Việt Nam. Ngoài ra, bản thân kế toán nên trau dồi kỹ năng sử dụng phần mềm, cập nhật những quy định mới của nhà nước ban hành, việc áp dụng đúng chế độ chính sách, thông tư và chuẩn mực kế toán phù hợp cũng là một vấn đề mà bản thân kế toán viên cần quan tâm.

\subsection{Hệ thống kiểm soát nội bộ}

Muốn hệ thống kiểm soát nội bộ của doanh nghiệp hoạt động hiệu quả, từng thành phần trong kiểm soát nội bộ phải hoạt động hiệu quả bao gồm: môi trường kiểm soát, quy trình đánh giá rủi ro tại đơn vị, hệ thống thông tin, các hoạt động kiểm soát, giám sát các kiểm soát. Tuy nhiên tại doanh nghiệp có quy mô nhỏ, vừa cần phải thực hiện làm sao cho hiệu quả dựa trên các nguồn lực sẵn có để hạn chế tốn kém về chi phí thực hiện. Cho nên khi xây dựng hệ thống kiểm soát nội bộ, doanh nghiệp cần chú ý một số vấn đề sau: Các hoạt động kiểm soát được quy định bằng văn bản; Thực hiện kiểm tra, giám sát thường xuyên và đối chiếu giữa các bộ phận; Sắp xếp, bố trí người làm kế toán phù hợp với năng lực của họ; Việc phân công công việc trùng lặp do ít nhân viên làm tăng nguy cơ sai sót tại doanh nghiệp.

Cho nên, việc xây dựng một hệ thống kiểm soát nội bộ tại các doanh nghiệp nhỏ và vừa trên tiêu chí tiết kiệm, hiệu quả góp phần không nhỏ trong việc ngăn ngừa sai sót có thể xảy ra trong quá trình thực hiện công việc kế toán.

\subsection{Môi trường pháp lý}

Hiện nay có một số vấn đề liên quan đến môi trường pháp lý làm tăng sai sót trên $\mathrm{BCTC}$ như: chuẩn mực, chế độ hướng dẫn về kế toán chưa quy định đầy đủ, kịp thời các vấn đề phát sinh tại trong thực tế tại doanh nghiệp; Có sự khác biệt giữa chính sách thuế và chế độ kế toán; Các quy định về kế toán bị chồng chéo, khó thực hiện; Có sự khác biệt về quy định giữa luật kế toán, chuẩn mực kế toán và chế độ kế toán. Do đó, cần thiết phải xây dựng hệ thống các văn bản pháp quy về kế toán rõ ràng, đầy đủ, phù hợp với đặc thù tại các doanh nghiệp. Ngoài ra, một trong các nguyên nhân lớn dẫn đến sai sót trong kế toán đó là hiện nay tại các doanh nghiệp nhỏ và vừa, hệ thống kế toán chủ yếu phục vụ cho việc lập báo cáo thuế điều này làm ảnh hưởng rất lớn đến việc cung cấp thông tin hữu ích cho việc ra quyết định. Cho nên, việc ban hành các chính sách về thuế phù hợp để thu hẹp sự khác biệt giữa thuế và kê toán sẽ góp phần không nhỏ trong việc giảm sự sai sót trong kế toán.

Bên cạnh đó, hội nghề nghiệp tổ chức các hội nghị, tập huấn chính sách mới, tiến hành trao đổi, giải đáp những thắc mắc phát sinh trong quá trình triển khai thực hiện liên quan đến các quy định mới, những điểm mới trong luật, nghị định cũng như các văn bản liên quan khác để tránh hiểu sai hoặc áp dụng chưa đúng tại các doanh nghiệp.

\section{4 Ửng dụng công nghệ thông tin}

Doanh nghiệp cần áp dụng hệ thống thông tin vào trong công tác kế toán nhằm hạn chế các sai sót về mặt xử lý dữ liệu, cũng như quản lý dữ liệu tại doanh nghiệp. Trong đó doanh nghiệp cần xây dựng cơ sở hạ tầng đầy đủ đáp ứng yêu cầu ứng dụng công nghệ thông tin trong công tác kế toán; Sử dụng phần mềm trong thực hiện công tác kế toán thay vì thực hiện thủ công hoặc excel; Khi sử dụng phần mềm kế toán được cập nhật, nâng cấp thường xuyên để đáp ứng sự thay đổi trong quy định về kế toán; Nhân viên cần được tập huấn sử dụng phần mềm; Phần mềm đáp ứng đầy đủ các nghiệp vụ phát sinh xảy ra tại doanh nghiệp.

\subsection{Kế hoạch đào tạo và bồi dưỡng}

Doanh nghiệp nên quan tâm bồi dưỡng về chuyên môn cho người làm kế toán đặc biệt trong giai đoạn chuyển đổi các quy định về kế toán. Có kế hoạch đào tạo định kỳ kiến thức về kế toán và thuế cho nhân viên, điều này có thể thuê mướn các chuyên gia hướng dẫn hoặc tạo điều kiện và hỗ trợ về mặt chi phí để nhân viên nâng cao trình bộ chuyên môn, khuyến khích các nhân viên học tập và nâng cao trình độ chuyên môn.

\subsection{Năng lực nhà lãnh đạo}

Nhận thức được tầm quan trọng về năng lực nhà lãnh đạo trong việc giảm thiểu sai sót về chất lượng thông tin trên Báo cáo tài chính trong doanh nghiệp, nhà quản lý doanh nghiệp cần phải: Truyền đạt thông tin rõ ràng của lãnh đạo đến nhân viên kế toán; Nhà lãnh đạo thường xuyên quan tâm đến tổ chức, vận hành công tác kế toán; Nhà lãnh đạo có sự am hiểu về kế toán; Lắng nghe ý kiến của nhân viên giúp nhà lãnh đạo cải thiện môi trường làm việc hiệu quả. 


\section{TÀI LIỆ THAM KHẢO}

[1] Bộ Kế hoạch và Đầu tư (2020). Sách trắng doanh nghiệp Việt Nam 2020. Nhà xuất bản thống kê, 40.

[2] Busuioceanu Steliana (2013). Correcting Accounting Errors And Acknowledging Them In The Earnings To The

[3] Period. Constantin Brâncuşi”" University of Taragu Jiu, Economy Series.

[4] Caster, P., Massey, D. W., \& Wright, A. (2000). Research on the nature, characteristics, and causes of accounting errors: The need for a multi-method approach. Journal of Accounting Literature, 19.

[5] Chambers, R. J. (1966). Accounting, Evaluation and Economic Behavior. Englewood Cliffs, N. J.: Prentice Hall.

[6] Chaney, P. K., \& Lewis, C. M. (1995). Earnings management and firm valuation under asymmetric information. Journal of corporate finance, 1(3-4), 319-345.

[7] Châu Quốc An (2017). Lý thuyết thể chế theo trường phái kinh tế học Tân thể chế và đổi mới thể chế kinh tế Việt Nam. Tạp chí phát triển khoa học và công nghệ: Chuyên san kinh tế - Luật và Quản lý, tập 1, số Q5-2017.

[8] Costi, Coman (2017). Corectarea erorilor contabile. Ceccar Business Magazine.

[9] Friedman, M. (1953). The methodology of positive economics.

[10] Hair, J. F., Black, W. C., Babin, B. J., \& Anderson, R. E. (2013). Multivariate data analysis: Pearson new international edition: Pearson Higher Ed

[11] Hongjiang Xu cùng các cộng sự (2003) . Key issues of accounting information quality management. ProQuest Central

[12] Littleton, A. C. (1977). Structure of accounting theory (No. 5). American Accounting Association.

[13] Löfgren, K. G., Persson, T., \& Weibull, J. W. (2002). Markets with asymmetric information: the contributions of George Akerlof, Michael Spence and Joseph Stiglitz. The Scandinavian Journal of Economics, 195-211.

[14] Lopatta, K., Buchholz, F., \& Kaspereit, T. (2016). Asymmetric information and corporate social responsibility. Business \& Society, 55(3), 458-488.

[15] Mattessich, R. (1995). Conditional-normative accounting methodology: incorporating value judgments and means-end relations of an applied science. Accounting, Organizations and Society, 20(4), 259-284.

[16] Ngô Thị Thu Hằng, Lê Thị Kim Sơn, và Nguyễn Thị Thùy Dung (2013). Tác động của hệ thống thông tin kế toán đến mức độ tồn tại gian lận và sai sót trong các doanh nghiệp nhỏ và vừa tại Hà Nội. Tạp chí Khoa học và Phát triển 2013, tập 11, số 4: 565-573.

[17] Nguyễn Công Phương, Nguyễn Trọng Hiếu và Nguyễn Mạnh Cường (2018). Sai sót báo cáo tài chính của công ty niêm yết trên thị trường chứng khoán Việt Nam. Tạp Chí Khoa học và Công nghệ Đại Học Đà Nã̃ng, Số 10(131) 2018.

[18] Nguyễn Đình Tuấn (2017). Các yếu tố ảnh hưởng đến mức độ gian lận và sai sót của kế toán viên ở các doanh nghiệp trong ngành giao thông vận tải TP.Hồ Chí Minh. Luận văn Thạc sĩ, Truờng Đại học Công nghệ TP.HCM. [19] Nguyễn Thế Hưng (2008). Hệ thống thông tin kế toán. Nhà xuất bản thống kê.

[20] Phạm Lê Ngọc Tuyết (2020). Đánh giá sai sót trong báo cáo tài chính tại các công ty xây lắp niêm yết trên thị trường chứng khoán Việt Nam. Tạp Chí Tài Chính, số 2 tháng 05/2018.

[21] Phạm Quốc Thuần (2016). Các nhân tố tác động đến chất lượng thông tin Báo cáo tài chính trong các doanh nghiệp tại Việt Nam. Luận văn Tiến sĩ kinh tế trường đại học Kinh tế Thành phố Hồ Chi Minh. 
[22] Phan Lê Thành Long (2010). Kế toán thực chứng: Hướng đúng phát triển của ngành kế toán Việt Nam?. Tạp chí Kế toán, số tháng 8 (7) 2010.

[23] Tabachnick, B. G., Fidell, L. S., \& Ullman, J. B. (2007). Using multivariate statistics (Vol. 5, pp. 481-498). Boston, MA: Pearson.

[24] Trần Thị Yến và cộng sự (2017). Nhân tố ảnh hưởng đến chất lượng báo cáo tài chính tại đơn vị sự nghiệp giáo dục công lập tại Bình Định. Tạp Chí Kế toán và Kiểm toán.

[25] Watts, R. L., \& Zimmerman, J. L. (1986). Positive accounting theory.

Ngày nhận bài: 25/04/2021

Ngày chấp nhận đăng: 20/07/2021 